\title{
Correction to: Constant severe imbalance following traumatic otoconial loss: a new explanation of residual dizziness
}

\author{
Stefan C. A. Hegemann ${ }^{1,2} \cdot$ Christian Weisstanner ${ }^{3} \cdot$ Arneborg Ernst $^{4} \cdot$ Dietmar Basta $^{4} \cdot$ Chris J. Bockisch $^{5}$
}

Published online: 25 June 2020

c) Springer-Verlag GmbH Germany, part of Springer Nature 2020

\section{Correction to: European Archives of Oto-Rhino-Laryngology https://doi.org/10.1007/s00405-020-05926-8}

In the original publication of the article, the second and third author's first and last names were swapped. The correct names are "Christian Weisstanner" and "Arneborg Ernst".

The original article was updated.

Publisher's Note Springer Nature remains neutral with regard to jurisdictional claims in published maps and institutional affiliations.

The original article can be found online at https://doi.org/10.1007/ s00405-020-05926-8.

Stefan C. A. Hegemann

s.hegemann@hin.ch

https://balance-clinic.ch/

1 Balance-clinic Zurich, Nüschelerstrasse 49, 8001 Zurich, Switzerland

2 Faculty of Medicine, Universität Zürich, Rämistrasse 71, 8006 Zurich, Switzerland

3 Medizinisch Radiologisches Institut Zurich (MRI-Zurich), Toblerstrasse 51, 8044 Zurich, Switzerland

4 Unfallkrankenhaus Berlin, Warener Str. 7, 12683 Berlin, Germany

5 University Hospital Zurich, Frauenklinikstrasse 24, 8091 Zurich, Switzerland 